\title{
Increase of efficiency of liquid humic fertilizers based on the use of combined feedstock
}

Arynov K.T., Auyeshov A.P., Faskhutdinov M.F., Zhilkibayev O.T. AspanTau LTD LLP, 255 Auyezov Street, Kalkaman-2, 050006 Almaty, Kazakhstan, tau_aspan@mail.ru

Keywords: brown coal, humic fertilizers, peat, vermicompost, extraction.

doi: 10.36291/HIT.2019.arynov.103

Liquid fertilizers produced from peat and vermicompost become more common in agriculture, especially in organic farming. As far as it is known, extracts of peat and vermicompost contain a complex of bioactive substances: vitamins, phytohormones, amino acids, humic acids and so on acting as important nutrient and growth-stimulating substances used for treatment of agricultural crops. The use of these components in liquid fertilizer improves efficiency.

However, liquid fertilizers have a number of disadvantages, the most significant of which is a high content of ballast substance - water. Long-distance transportation of liquid fertilizer increases transportation costs and the need in increase of concentration of liquid fertilizers or, in other words, reduction of product cost per hectare of land is crucial for research works for countries with vast areas such as Russian Federation and Republic of Kazakhstan.

We are working on production of new liquid humic fertilizers using combined feedstock such as brown coal, peat and vermicompost. We have produced samples of liquid fertilizers with an increased content of humic acids (25 times) preserving useful properties of peat and vermicompost extracts. This has been achieved by mixing two different extracts of brown coal one of which is rich with salts of humic acid and the second one as the source of a number of bioactive substances.

The produced samples were studied using a screening electron microscope JSM6490LV, systems of energy-disperse microanalysis INCA Energy and structural analysis HKL-Basic. It was shown that the samples contain useful elements such as $\mathrm{K}, \mathrm{Ca}, \mathrm{Mg}$ and Fe. IR Fourier spectra of samples were made using spectrometer Shimadzu IR Prestige21 with attenuated total reflection Miracle by Pike Technologies.

Experimental researching of new products are still in progress. 